\title{
Ampakine CX1942 attenuates opioid-induced respiratory depression and corrects the hypoxaemic effects of etorphine in immobilized goats (Capra hircus)
}

\author{
Anna J Haw*, Leith CR Meyer*, $\dagger$, John J Greer \& \& Andrea Fuller*, $\dagger$ \\ * Brain Function Research Group, Faculty of Health Sciences, School of Physiology, University of the \\ Witwatersrand, Parktown, South Africa \\ †Department of Paraclinical Sciences, Faculty of Veterinary Science, University of Pretoria, Onderstepoort, \\ South Africa \\ ¥Department of Physiology, Faculty of Medicine and Dentistry, University of Alberta, Edmonton, AB, Canada \\ Correspondence: Anna J Haw, Brain Function Research Group, Faculty of Health Sciences, School of Physiology, \\ University of the Witwatersrand, 7 York Road, Parktown 2193, South Africa. E-mail: anna.haw@wits.ac.za
}

\section{Abstract}

Objectives: To determine whether CX1942 reverses respiratory depression in etorphineimmobilized goats, and to compare its effects with those of doxapram hydrochloride.

Study design: A prospective, crossover experimental trial conducted at 1753 m.a.s.I.

Animals: Eight adult female Boer goats (Capra hircus) with a mean \pm standard deviation mass of $27.1 \pm 1.6 \mathrm{~kg}$.

Methods: Following immobilization with $0.1 \mathrm{mg} \mathrm{kg}^{-1}$ etorphine, goats received one of doxapram, CX1942 or sterile water intravenously, in random order in three trials.

Respiratory rate, ventilation and tidal volume were measured continuously. Arterial blood samples for the determination of $\mathrm{PaO}_{2}, \mathrm{PaCO}_{2}, \mathrm{pH}$ and $\mathrm{SaO}_{2}$ were taken 2 minutes before and then at 5 minute intervals after drug administration for 25 minutes.

Results: Doxapram corrected etorphine-induced respiratory depression but also led to arousal and hyperventilation at 2 minutes after its administration, as indicated by the low $\mathrm{PaCO}_{2}(27.8 \pm 4.5 \mathrm{mmHg})$ and ventilation of $5.32 \pm 5.24 \mathrm{~L}_{\text {minute }}{ }^{-1}$ above pre-immobilization values. CX1942 improved respiratory parameters and corrected etorphine's hypoxaemic effects more gradually than did doxapram, with a more sustained improvement in $\mathrm{PaO}_{2}$ and $\mathrm{SaO}_{2}$ in comparison with the control trial.

Conclusions: CX1942 attenuated opioid-induced respiratory depression and corrected the hypoxaemic effects of etorphine in immobilized goats.

Clinical relevance: Ampakines potentially offer advantages over doxapram, a conventional treatment, in reversing etorphine-induced respiratory depression without causing unwanted side effects, particularly arousal, in immobilized animals. 


\section{Introduction}

For more than 50 years, etorphine's advantageous pharmacodynamics have enabled veterinarians to immobilize free-ranging wild animals for management and veterinary interventions. However, opioid-induced respiratory depression remains a significant, and potentially life-threatening, side effect of chemical immobilization. Opioid-induced respiratory depression is mediated mainly via direct activation of $\mu$-opioid receptors, which are abundantly expressed in brainstem respiratory control centres (Pattinson 2008; Dahan et al. 2010). Opioids also depress the hypoxic ventilatory response and hypercapnic ventilatory response through the depression of central chemoreception (Pattinson 2008).

The desirable effects of etorphine, such as analgesia, sedation and catatonia, are also produced through activation of $\mu$-opioid receptors (Dahan et al. 2010). Thus opioidantagonists such as naltrexone and naloxone, which are effective at counteracting opioidinduced respiratory depression, will also antagonize analgesia, sedation and catatonia, which is undesirable when etorphine is used as a chemical immobilizing agent in wildlife.

Doxapram, an analeptic agent, is often used to stimulate respiration in opioid-immobilized wild animals (Burroughs et al. 2012). Although respiration is significantly improved following the administration of doxapram, the effects are short-lived and general central nervous system stimulation can result in undesirable side effects (Yost 2006).

More recently, a novel approach using ampakines has been developed for alleviating respiratory depression caused by disease and drug administration (Ren et al. 2006, 2009, 2012, 2013, 2015; El Mallah et al. 2015). Ampakines are a structurally diverse family of small molecules that readily cross the blood-brain barrier and bind to an allosteric site on the $\alpha$ amino-3-hydroxy-5-methyl-4-isoxazolepropionic acid (AMPA) receptor to enhance fast, excitatory transmission (Lynch 2006). AMPA receptor-mediated conductances are important contributors to respiratory rhythmogenesis and inspiratory drive to cranial and spinal motoneurons (Greer et al. 1991; Funk et al. 1993; Pace et al. 2007). Indeed, ampakines suitable for oral administration have been shown to counteract opioid-induced respiratory depression without affecting $\mu$-opioid analgesia, in both rats and humans (Ren et al. 2006, 2009; Oertel et al. 2010). However, whether an injectable ampakine formulation will reverse respiratory depression, without affecting the immobilizing properties of etorphine, is not yet known.

Here, we used the goat (Capra hircus), a domestic artiodactyl, as a model to evaluate the effectiveness of an ampakine, CX1942, in attenuating opioid-induced respiratory depression in etorphine-immobilized ungulates. CX1942 is a novel, water-soluble, low-impact ampakine that is rapidly absorbed and pharmacologically active. This model enabled us to evaluate CX1942 without the background of a severe stress response that normally accompanies the capture of wild animals. We aimed to compare the effects of CX1942 with those of the known respiratory stimulant doxapram in order to test the hypothesis that CX1942 would be more effective than doxapram in attenuating etorphine-induced respiratory depression. 


\section{Materials and methods}

This project was approved by the University of the Witwatersrand Animal Ethics Screening Committee (clearance 2013/26/04) and adhered to the ARRIVE guidelines for reporting in vivo experiments (Kilkenny et al. 2010). We used eight healthy, adult, female Boer goats (C. hircus) with a mean \pm standard deviation (SD) body mass of $27.1 \pm 1.6 \mathrm{~kg}$. A sample size of eight was chosen based on the statistically significant and clinically relevant results of a previous controlled repeated-measures study in which eight animals had been used (Meyer et al. 2006). The goats were housed together in temperature-controlled indoor pens in the Central Animal Services, University of the Witwatersrand, South Africa, at an altitude of 1753 m.a.s.l., on a 12:12 hour light:dark cycle (lights came on at 06.00 hours). Air temperature ranged between $21^{\circ} \mathrm{C}$ and $23{ }^{\circ} \mathrm{C}$ and relative humidity between $23 \%$ and $47 \%$. The goats had access to water ad libitum and were fed on hay and sheep concentrate pellets. Over a period of 6 weeks, before the start of data collection, each goat was habituated to being restrained in sternal recumbency on a work table with a face mask over its muzzle.

All measurements were made indoors between 08.00 hours and 13.30 hours. Barometric pressure, measured by the onboard barometer of the blood gas analyser, ranged from 622.4 to $626.2 \mathrm{mmHg}(83.0-83.5 \mathrm{kPa})$. The partial pressure of inspired oxygen therefore was about $131 \mathrm{mmHg}(17.5 \mathrm{kPa})$, about $30 \mathrm{mmHg}$ lower than the partial pressure of inspired oxygen at sea level.

\section{Experimental procedures}

The experiment consisted of three trials whereby each goat was given each of the following treatments in a random order at 2 week intervals: etorphine and sterile injectable water (control); etorphine and doxapram, and etorphine and CX1942. Trial randomization was determined using a computer-generated random number sequence. Etorphine hydrochloride (Captivon $9.8 \mathrm{mg} \mathrm{mL}^{-1}$; Wildlife Pharmaceuticals Pty Ltd, South Africa) was injected intramuscularly (IM) into the right gluteal muscle (time 0 ) at a dose of $0.1 \mathrm{mg} \mathrm{kg}^{-1}$. This dose adequately immobilized and sedated the goats for the duration of the 30 minute experimental period. Doxapram hydrochloride (Dopram-Fresenius $20 \mathrm{mg} \mathrm{mL}^{-1}$; Bodene Pty Ltd, South Africa) was injected intravenously (IV) at a dose of $1 \mathrm{mg} \mathrm{kg}^{-1}$. CX1942 (Cortex Pharmaceuticals, Inc., NJ, USA) was made up to a concentration of $50 \mathrm{mg} \mathrm{mL}^{-1}$ by dissolving the solute in sterile physiological saline [0.9\% NaCl; Fresenius Kabi Manufacturing SA (Pty) Ltd, South Africa], and was injected IV at a dose of $20 \mathrm{mg} \mathrm{kg}^{-1}$. This dose was established in a pilot dose-response study, in which a higher dose was not more effective, and a lower dose did not produce a consistent response. In the control treatment, $2 \mathrm{~mL}$ of sterile injectable water [Water for Injection; Kyron Laboratories (Pty) Ltd, South Africa] was injected IV. Doxapram, CX1942 and sterile water (control) were each injected at 8 minutes after the etorphine during the respective trials.

The goats were weighed before each trial and were starved for at least 12 hours before the trial to reduce the risk for bloat and regurgitation of ingesta. In each trial, the goat was brought from its pen to the laboratory and placed on a table in sternal recumbency. The horns were held by a handler and the goat's head positioned so that the neck was aligned 
with the spinal column and the head was elevated above the thorax with the nose pointing downwards.

Both ears were shaved and a topical local anaesthetic, amethocaine hydrochloride (Anethaine Cream; Winthrop Pharmaceuticals Pty Ltd, South Africa), was applied. The ears were then swabbed with 5\% chlorhexidine gluconate [Hibitane; AstraZeneca SA (Pty) Ltd, South Africa] in 100\% ethanol. A 22 gauge catheter (Introcan; B Braun, Melsungen AG, Germany) was placed in one of the auricular arteries and connected to a three-way stopcock valve [Sabex Manufacturing (Pty) Ltd, South Africa], which was secured to the ear with adhesive tape (Leukoplast; BSN Medical GmbH, Germany). A second 22 gauge catheter was placed in an auricular vein in the opposite ear to facilitate IV drug administration.

A clear canine anaesthetic face mask (J-298C; Jorgensen Laboratories, Inc., CO, USA) was placed over the nose and mouth of the goat. A tight seal between the goat's muzzle and the face mask was achieved using a modified latex glove. The face mask was connected to a two-way valve which directed all expired air into the PowerLab Exercise Physiology System (ADInstruments Pty Ltd, NSW, Australia), via a respiratory flow head (MLT300L;

ADInstruments Pty Ltd) linked to a spirometer (ML141; ADInstruments Pty Ltd) and a gas mixing chamber (MLA245; ADInstruments Pty Ltd), in which expired gas temperature was measured by a thermistor pod (ML309; ADInstruments Pty Ltd). The data from these modules were collected via the PowerLab 8/30 amplifier (ML870; ADInstruments Pty Ltd) and integrated with Metabolic Module software (ADInstruments Pty Ltd) to measure minute ventilation, tidal volume and respiratory rate $\left(f_{R}\right)$. Before each set of measurements, the spirometer was zeroed and calibrated using a $3 \mathrm{~L}$ calibration syringe.

Naltrexone hydrochloride (Trexonil $50 \mathrm{mg} \mathrm{kg}^{-1}$; Wildlife Pharmaceuticals Pty Ltd) was administered IV at 28 minutes after the etorphine injection at a dose of $2 \mathrm{mg} \mathrm{kg}^{-1}$, which adequately reversed the effects of etorphine within 1 minute of administration. Data were recorded for 3 minutes before the injection of etorphine until 1 minute after the administration of naltrexone. A $0.5 \mathrm{~mL}$ arterial blood sample was drawn 2 minutes before etorphine injection and at 5, 10, 15, 20 and 25 minutes thereafter. The catheter was flushed with $2 \mathrm{~mL}$ heparinized saline after each sample. Arterial $\mathrm{pH}$, partial pressures of oxygen $\left(\mathrm{PaO}_{2}\right)$, and carbon dioxide $\left(\mathrm{PaCO}_{2}\right)$, and haemoglobin oxygen saturation $\left(\mathrm{SaO}_{2}\right)$ were measured immediately after sample collection using a pre-calibrated blood gas analyser with pre-calibrated blood gas cassettes [Roche OPTI CCA Analyzer + OPTI cassette B; Kat Medical (Pty) Ltd, South Africa]. Partial pressures were measured and reported at $37^{\circ} \mathrm{C}$. We considered the goats to have etorphine-induced hypoxaemic effects when $\mathrm{PaO}_{2}$ values were significantly lower than those before immobilization. We did not use a standardized cut-off value (e.g. $<60 \mathrm{mmHg}$ ) to define hypoxaemia because the altitude at which our study was conducted had an effect on the partial pressures of arterial gases in the goats.

The quality of immobilization was scored at 1 minute after each arterial blood sample on a scale ranging from 1 (fully awake) to 5 (life-threatening immobilization) (Table 1). 
Table 1. Scale used to score the level of immobilization in goats

\begin{tabular}{|l|l|l|}
\hline $\begin{array}{l}\text { Score } \\
1\end{array}$ & $\begin{array}{l}\text { Fully awake } \\
\text { Light plane of immobilization, palpebral and ear flick reflexes still present; movement of one or more } \\
\text { body parts (tail, ear, head, limb) } \\
\text { Appropriately immobilized with reduced but present palpebral and ear flick reflexes; occasional } \\
\text { movement of one body part } \\
4\end{array}$ & $\begin{array}{l}\text { Appropriately immobilized with absent palpebral and ear flick reflexes; no movement of any body parts } \\
\text { Immobilized to a life-threatening level; no response to excessive stimulation }\end{array}$ \\
\hline 5
\end{tabular}

\section{Data analysis}

GraphPad Prism Version 6.00 for Mac OS X (GraphPad Software, Inc., CA, USA) was used for statistical analyses. All results are reported as the mean \pm SD. A $p$-value of $<0.05$ was considered to indicate statistical significance. For all the variables measured by the blood gas analyser and PowerLab Exercise Physiology System, a two-way repeated-measures analysis of variance (anova) and Tukey's multiple comparisons test were used to test for differences between responses to doxapram hydrochloride, CX1942 and sterile water (control) at -2, 5, 10, 15, 20 and 25 minutes, and between time-points for each intervention. Immobilization scores were not statistically compared.

\section{Results}

\section{Respiratory rate}

Respiratory rates in the goats during the three trials changed over time $\left(F_{(5,105)}=49.51\right.$, $p<0.0001)$ and differences were observed between trials $\left(F_{(2,21)}=3.84, p=0.04\right)$ (Fig. 1a). Before etorphine was injected ( -2 minutes), $f_{\mathrm{R}}$ values were similar across trials.

Administration of etorphine resulted in hypopnea at 5 minutes in all three trials. Injections of sterile water (control) or CX1942 did not improve $f_{\mathrm{R}}$ at any time-point. However, doxapram administration resulted in increased $f_{\mathrm{R}}$ at 10,15 and 25 minutes, although $f_{\mathrm{R}}$ did not return to baseline values. 

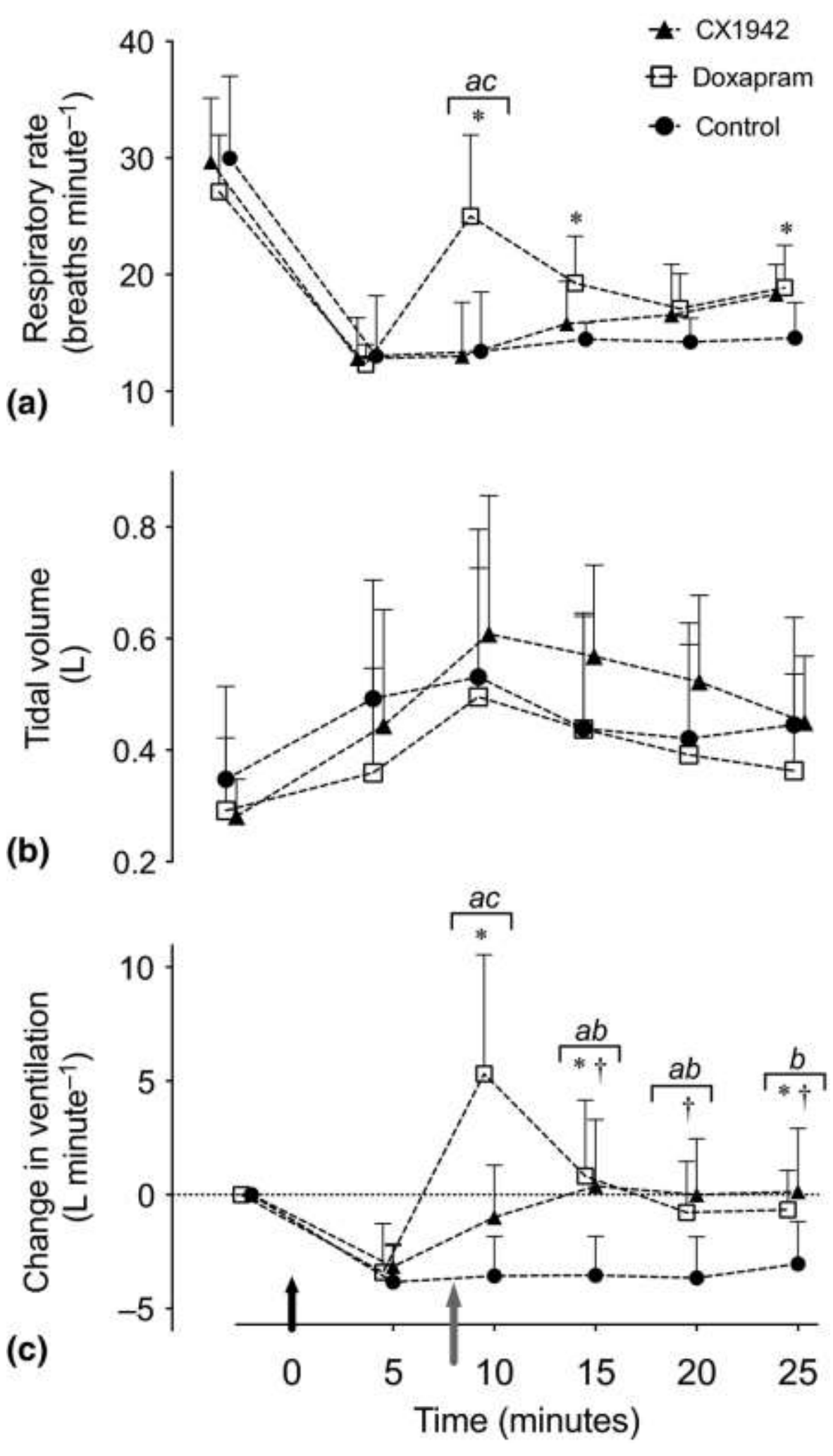

Figure 1. Effects of doxapram $\left(1 \mathrm{mg} \mathrm{kg}^{-1}\right), \mathrm{CX} 1942\left(20 \mathrm{mg} \mathrm{kg}^{-1}\right)$ and sterile water (control) injected intravenously (time $=8$ minutes, illustrated by the grey arrow) in etorphine-immobilized goats on (a) respiratory rate, (b) tidal volume and (c) change in ventilation (mean $\pm S D, n=8$ ). The black arrow (time $=0$ ) indicates the time-point at which etorphine $\left(0.1 \mathrm{mg} \mathrm{kg}^{-1}\right)$ was administered intramuscularly. The symbols * and + indicate when values in the doxapram and CX1942 trials, respectively, differ from those at 5 minutes. Differences between the treatment trials are indicated by the letters $a$ (doxapram versus control), $b$ (CX1942 versus control) and $c$ (doxapram versus CX1942) (repeated-measures two-way anova). 


\section{Tidal volume}

In all treatments, including the control, tidal volumes in the goats were higher at 10 minutes than at baseline (pre-immobilization, -2 minutes; $p<0.05$ ) and at 5 minutes, and thereafter did not differ from one another (Fig. 1b). There were no differences between the treatments in tidal volume at any time-point $\left(F_{(2,21)}=0.65, p=0.53\right)$. However, tidal volume in goats in the CX1942 treatment increased so that it was higher at 10,15, 20 and 25 minutes than prior to immobilization at -2 minutes $(p<0.05)$.

\section{Change in ventilation}

Following etorphine administration (5 minutes), ventilation decreased in all groups (Fig. 1c). The administration of doxapram and CX1942 improved ventilation compared with when the goats received the control treatment $\left(F_{(2,21)}=8.74, p=0.002\right)$. At 2 minutes after doxapram administration, ventilation increased to $5.32 \pm 5.24 \mathrm{~L}_{\text {minute }}{ }^{-1}$ above pre-immobilization levels $(-2$ minutes versus 10 minutes; $p<0.0001)$. In one goat, ventilation increased by more than $16 \mathrm{~L}$ minute ${ }^{-1}$ above pre-immobilization levels after doxapram, which contributed to the large SD at 10 minutes. Shortly after this hyperventilatory response, ventilation in the goats that had received doxapram decreased to pre-immobilization levels at 15, 20 and 25 minutes. When ventilation in of the goats following the control treatment was compared to that following doxapram, doxapram administration resulted in higher levels of ventilation at the at 10, 15 and 20 minutes, but not at 25 minutes. CX1942 led to a gradual increase in ventilation so that ventilation at 15,20 and 25 minutes was higher $(p<0.05)$ than at 5 minutes and did not differ from pre-immobilization levels. In addition, the goats in the CX1942 treatment had higher ventilation rates at 15, 20 and 25 minutes compared to when they received the control treatment $(p<0.05)$.

\section{Arterial blood gases}

$\mathrm{PaO}_{2}$ in the goats changed over time $\left(F_{(5,105)}=51.82, p<0.0001\right)$ and between treatments $\left(F_{(2,21)}=8.2, p=0.002\right)$ (Fig. 2a). At 5 minutes after the administration of etorphine, $\mathrm{PaO}_{2}$ had decreased in all groups. When the goats did not receive any treatment intervention (control), $\mathrm{PaO}_{2}$ gradually improved but the hypoxaemic effects of etorphine were not corrected at any time during the immobilization period. Doxapram administration resulted in an immediate increase in $\mathrm{PaO}_{2}$; at 10 minutes $\mathrm{PaO}_{2}$ was higher than before the intervention $(p<0.0001)$ and higher than at subsequent time-points $(p<0.0001)$, but this value was not sustained and decreased to below pre-immobilization levels at 20 minutes to become comparable with control values. However, the administration of CX1942 to immobilized goats resulted in sustained improvement in $\mathrm{PaO}_{2}$ compared with that when the goats received the control treatment and corrected the hypoxaemic effects of etorphine $(p>0.05)$ 

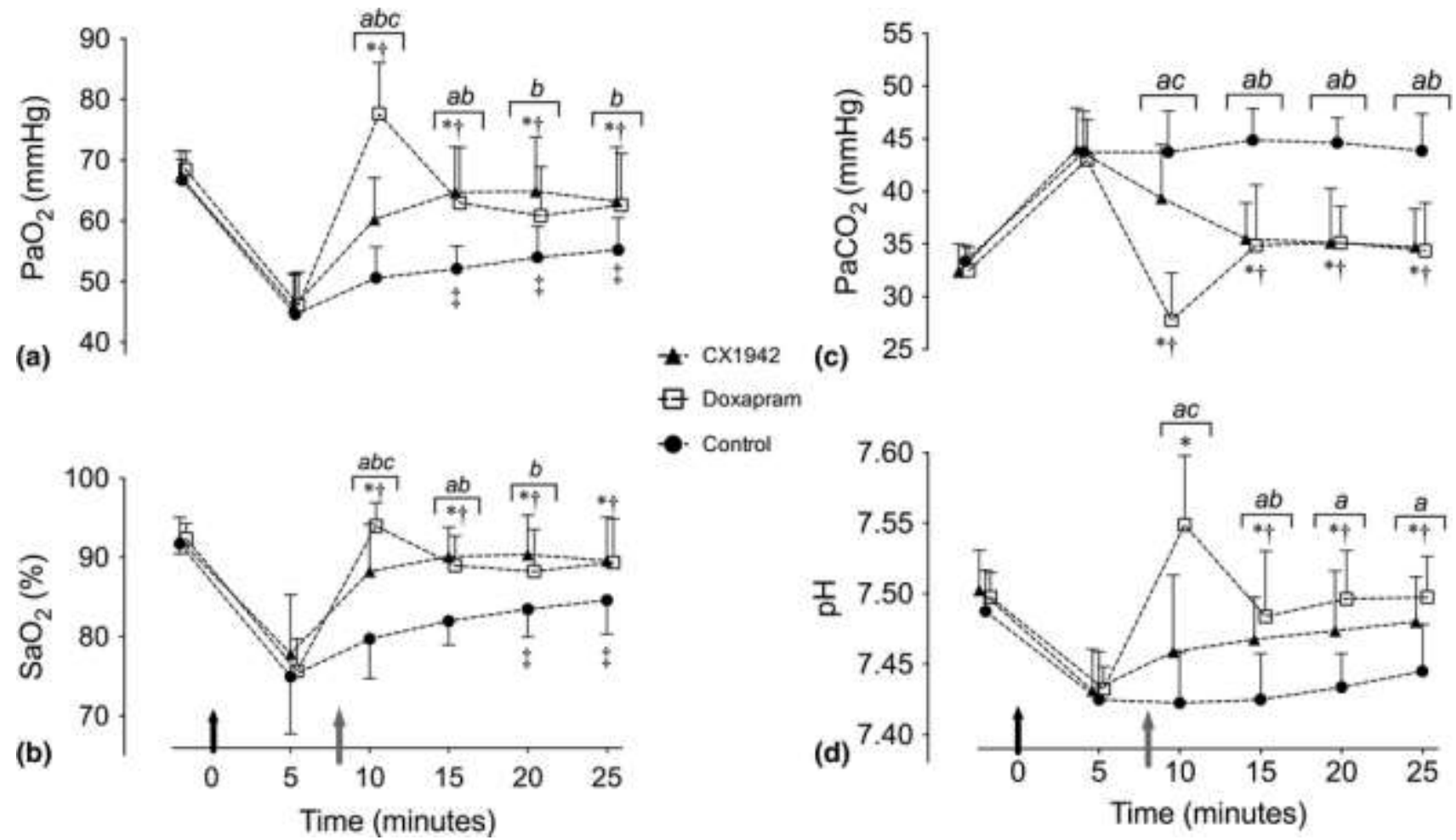

Figure 2. Effects of doxapram $\left(1 \mathrm{mg} \mathrm{kg}^{-1}\right), \mathrm{CX} 1942\left(20 \mathrm{mg} \mathrm{kg}^{-1}\right)$ and sterile water (control) injected intravenously (time $=8$ minutes, illustrated by the grey arrow) in etorphine-immobilized goats on mean \pm standard deviation (a) partial pressure of arterial oxygen $\left(\mathrm{PaO}_{2}\right)$, (b) haemoglobin oxygen saturation $\left(\mathrm{SaO}_{2}\right),(\mathrm{c})$ partial pressure of arterial carbon dioxide $\left(\mathrm{PaCO}_{2}\right)$, and $(\mathrm{d})$ arterial $\mathrm{pH}(n=8)$. The black arrow (time $=0)$ indicates the time-point at which etorphine $\left(0.1 \mathrm{mg} \mathrm{kg}^{-1}\right)$ was administered intramuscularly. The symbols *, † and $\ddagger$ indicate when values in the doxapram, CX1942 and control trials, respectively, differ from those at 5 minutes. Differences between the treatments at specific time-points are indicated by the letters $a$ (doxapram versus control), $b$ (CX1942 versus control) and $c$ (doxapram versus CX1942) (repeated-measures two-way anova).

Similarly, etorphine, doxapram and CX1942 led to changes in $\mathrm{SaO}_{2}$ values $\left(F_{(5,123)}=29.11\right.$, $p<0.0001$ ) that paralleled the changes observed in $\mathrm{PaO}_{2}$ (Table 2, Fig. $2 \mathrm{~b}$ ).

Table 2. Absolute values (mean $\pm \mathrm{SD}, n=8$ ) of respiratory rate (breaths minute ${ }^{-1}$ ), tidal volume $(\mathrm{L}$ ), ventilation $\left(\mathrm{L}\right.$ minute $\left.{ }^{-1}\right), \mathrm{PaO}_{2}(\mathrm{mmHg}[\mathrm{kPa}]), \mathrm{SaO}_{2}(\%) \mathrm{PaCO}_{2}(\mathrm{mmHg}[\mathrm{kPa}])$ and $\mathrm{pH}$

\begin{tabular}{|c|c|c|c|c|c|c|c|}
\hline \multirow{2}{*}{ Variable } & \multirow{2}{*}{ Group } & \multicolumn{6}{|c|}{ Time-point (minutes) } \\
\hline & & $\underline{-2}$ & $\underline{\mathbf{5}}$ & $\underline{10}$ & $\underline{15}$ & $\underline{20}$ & $\underline{25}$ \\
\hline \multirow{4}{*}{$\begin{array}{l}f_{\mathrm{R}} \\
\text { (breaths minute }{ }^{-1} \text { ) }\end{array}$} & Control & $30 \pm 7$ & $13 \pm 5^{*}$ & $13 \pm 5^{*}$ & $14 \pm 1^{*}$ & $14 \pm 2^{*}$ & $15 \pm 3^{*}$ \\
\hline & Doxapram & $27 \pm 5$ & $12 \pm 2^{*}$ & $25 \pm 7+$ & $19 \pm 4^{*},+$ & $17 \pm 3^{*}$ & $19 \pm 4^{*},+$ \\
\hline & CX1942 & $30 \pm 5$ & $13 \pm 4^{*}$ & $13 \pm 5^{*}$ & $16 \pm 4^{*}$ & $17 \pm 4^{*}$ & $18 \pm 3^{*}$ \\
\hline & Control & $0.35 \pm 0.17$ & $0.49 \pm 0.21$ & $0.53 \pm 0.26 *$ & $0.44 \pm 0.20$ & $0.42 \pm 0.21$ & $0.45 \pm 0.19$ \\
\hline \multirow[t]{3}{*}{ Tidal volume (L) } & Doxapram & $0.29 \pm 0.13$ & $0.36 \pm 0.19$ & $0.50 \pm 0.23 *$ & $0.44 \pm 0.21$ & $0.39 \pm 0.20$ & $0.36 \pm 0.17$ \\
\hline & CX1942 & $0.28 \pm 0.07$ & $0.44 \pm 0.21$ & $0.61 \pm 0.25^{*}$ & $0.57 \pm 0.16^{*}$ & $0.52 \pm 0.15^{*}$ & $0.45 \pm 0.12 *$ \\
\hline & Control & $9.82 \pm 4.62$ & $5.98 \pm 3.14^{*}$ & $6.25 \pm 3.10^{*}$ & $6.27 \pm 2.96^{*}$ & $6.16 \pm 2.92 *$ & $6.78 \pm 3.30^{*}$ \\
\hline \multirow{2}{*}{$\begin{array}{l}\text { Ventilation } \\
\left(\text { L minute }^{-1}\right)\end{array}$} & Doxapram & $7.82 \pm 3.86$ & $4.41 \pm 2.26^{*}$ & $13.14 \pm 7.80 *,+$ & $8.64 \pm 5.08+$ & $7.05 \pm 4.35$ & $7.17 \pm 4.46^{\dagger}$ \\
\hline & CX1942 & $8.23 \pm 1.96$ & $5.07 \pm 1.31^{*}$ & $7.24 \pm 2.92$ & $8.60 \pm 2.31+$ & $8.23 \pm 2.18^{\dagger}$ & $8.37 \pm 2.46{ }^{\dagger}$ \\
\hline \multirow{2}{*}{$\mathrm{PaO}_{2}(\mathrm{mmHg})[\mathrm{kPa}]$} & Control & $\begin{array}{l}67 \pm 3 \\
{[8.4 \pm 0.4]}\end{array}$ & $\begin{array}{l}45 \pm 7 \\
{[6.0 \pm 0.9]^{*}}\end{array}$ & $\begin{array}{l}51 \pm 5 \\
{[6.8 \pm 0.7]^{*}}\end{array}$ & $\begin{array}{l}52 \pm 4 \\
{[6.9 \pm 0.5]^{*},+}\end{array}$ & $\begin{array}{l}54 \pm 5 \\
{[7.2 \pm 0.7]^{*},+}\end{array}$ & $\begin{array}{l}55 \pm 5 \\
{[7.3 \pm 0.7]^{*},+}\end{array}$ \\
\hline & Doxapram & $\begin{array}{l}69 \pm 3 \\
{[9.2 \pm 0.4]}\end{array}$ & $\begin{array}{l}46 \pm 5 \\
{[6.1 \pm 0.7]^{*}}\end{array}$ & $\begin{array}{l}78 \pm 8 \\
{[10.4 \pm 1.1] *, \dagger}\end{array}$ & $\begin{array}{l}63 \pm 9 \\
{[8.4 \pm 1.2]^{\dagger}}\end{array}$ & $\begin{array}{l}61 \pm 8 \\
{[8.1 \pm 1.1]^{*},+}\end{array}$ & $\begin{array}{l}63 \pm 9 \\
{[8.4 \pm 1.2]^{\dagger}}\end{array}$ \\
\hline
\end{tabular}




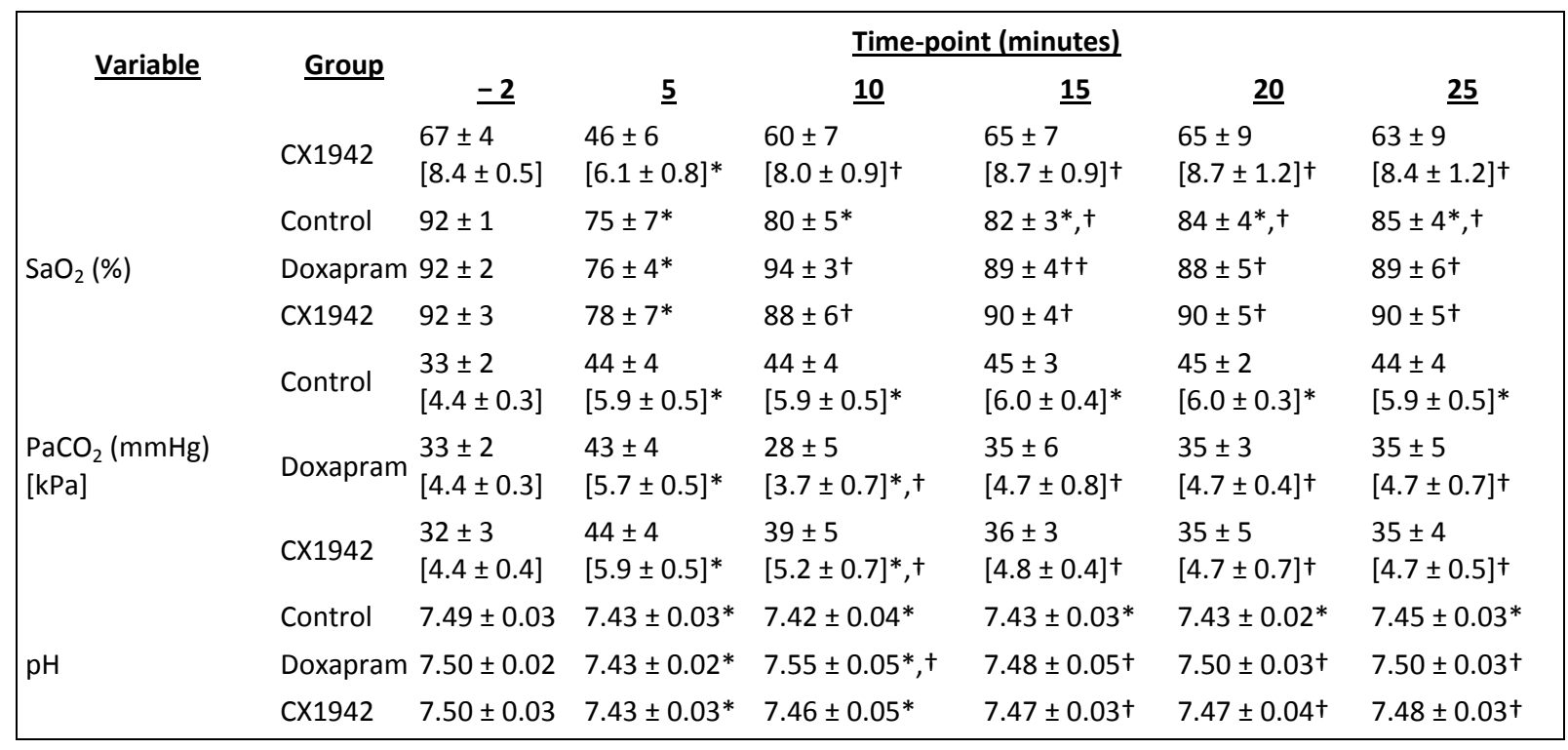

$f_{\mathrm{R}}$, respiratory rate; $\mathrm{PaO}_{2}$, partial pressure of arterial oxygen; $\mathrm{SaO}_{2}$, haemoglobin oxygen saturation; $\mathrm{PaCO}_{2}$, partial pressure of arterial carbon dioxide. *Significantly different from value at -2 minutes $(p<0.05)$. ${ }^{\dagger}$ Significantly different from value at 5 minutes $(p<0.05)$.

As expected, the etorphine-induced hypopnea led to a significant increase $\left(F_{(5,105)}=40\right.$, $p<0.0001$ ) in $\mathrm{PaCO}_{2}$ at 5 minutes (Fig. 2c). When the goats did not receive any treatment (control), $\mathrm{PaCO}_{2}$ remained elevated throughout the immobilization period and values did not differ $(p>0.05)$ between 25 minutes and 5 minutes. Doxapram administration resulted in an immediate and significant reduction in $\mathrm{PaCO}_{2}$ at 10 minutes to a level below that at -2 minutes $(p<0.01)$, although $\mathrm{PaCO}_{2}$ returned to levels similar to that at -2 minutes by 15 , 20 and 25 minutes $(p>0.05)$. CX1942 also resulted in a decrease in $\mathrm{PaCO}_{2}$ so that $\mathrm{PaCO}_{2}$ in all samples after CX1942 administration was lower than that at 5 minutes $(p<0.05)$. The decrease in $\mathrm{PaCO}_{2}$ following CX1942 administration, however, was more gradual and less exaggerated than that observed after doxapram administration.

In parallel with the elevated $\mathrm{PaCO}_{2}$ in goats following etorphine administration, $\mathrm{pH}$ decreased in all trials $\left(F_{(5,150)}=20, p<0.0001\right)$ (Fig. $\left.2 d\right)$. When the goats did not receive any treatment intervention, $\mathrm{pH}$ remained below pre-immobilization values $(p<0.01)$ throughout the immobilization period. Doxapram IV resulted in an immediate increase in $\mathrm{pH}$ at 10 minutes. Indeed, doxapram administration resulted in a higher $\mathrm{pH}$ compared with the control at all time-points following the intervention $(p<0.01)$, and $\mathrm{pH}$ at 15,20 and 25 minutes did not differ from that at -2 minutes $(p>0.05)$. CX1942 administration also led to a rise in $\mathrm{pH}$, but the increase was more gradual than that following doxapram: values at 15,20 and 25 minutes were higher than that at 5 minutes $(p<0.01)$ and did not differ from pre-immobilization values $(p>0.05)$. CX1942 did not increase $\mathrm{pH}$ compared with sterile water (control) except at 15 minutes $(p<0.05)$.

\section{Movement}

Following the administration of etorphine, goats in the control and doxapram trials had a median immobilization score (Table 1) of 4, whereas goats in the CX1942 treatment had a median immobilization score of 3 . This level of immobilization (score: 4) was maintained 
throughout the experimental procedure in the control trial (Fig. 3). Doxapram administration, however, resulted in a decrease in the level of immobilization with median scores of 2 (light plane of immobilization with occasional body movement) at 10, 15 and 20 minutes. By contrast, the administration of CX1942 did not alter the degree of immobilization on a gross level and the median immobilization score remained consistent at 3 throughout the experimental period.

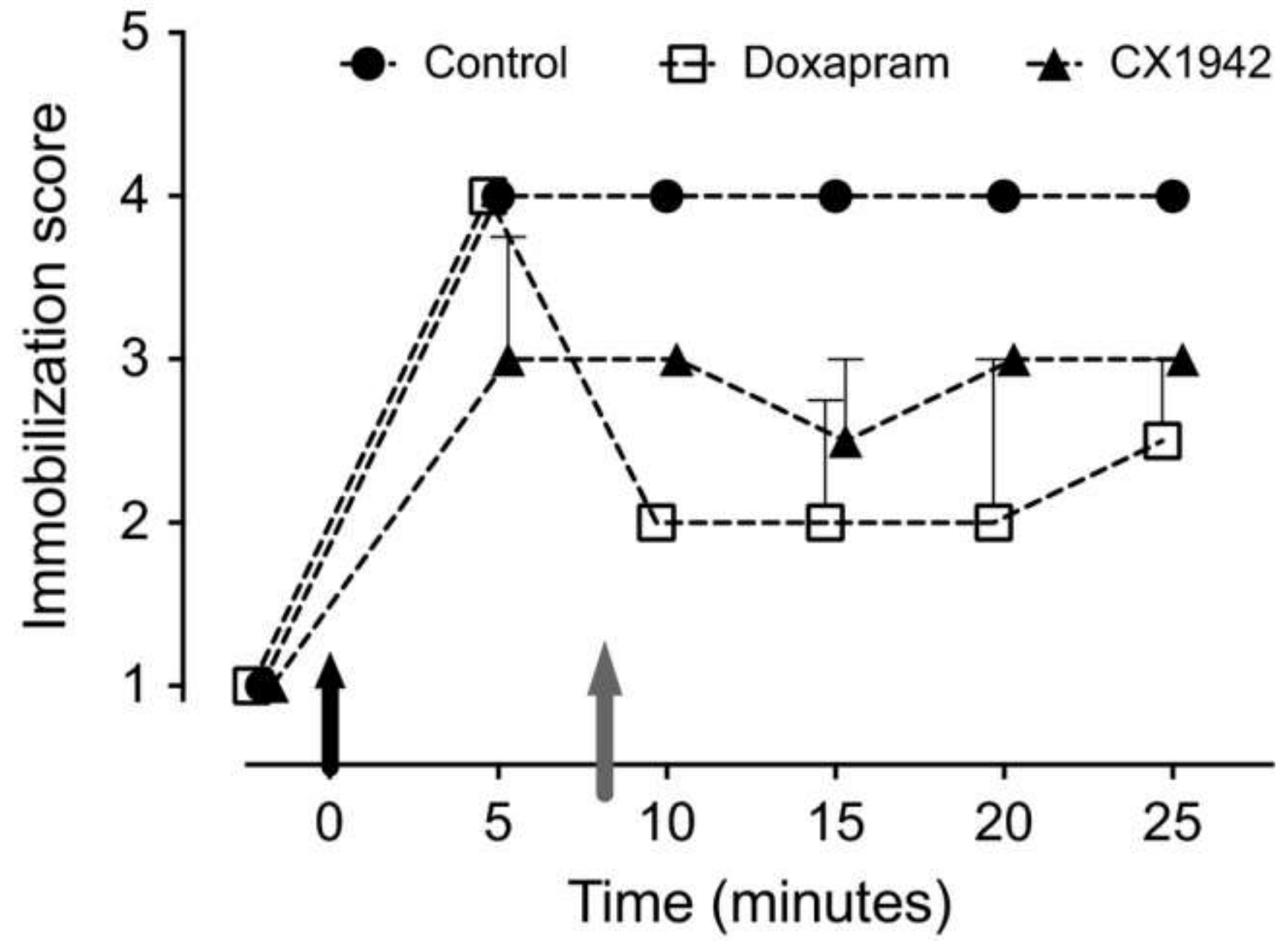

Figure 3. Effects of doxapram $\left(1 \mathrm{mg} \mathrm{kg}^{-1}\right), \mathrm{CX} 1942\left(20 \mathrm{mg} \mathrm{kg}^{-1}\right)$ and sterile water (control) injected intravenously (time $=8$ minutes, illustrated by the grey arrow) in etorphine-immobilized goats on immobilization score (Table 1) (median \pm interquartile range, $n=8)$. The black arrow (time $=0$ ) indicates the time-point at which etorphine $\left(0.1 \mathrm{mg} \mathrm{kg}^{-1}\right)$ was administered intramuscularly.

\section{Discussion}

The present study is one of the first to examine the effects of an ampakine on etorphineinduced respiratory depression. We found that the administration of CX1942 led to an improvement in respiratory parameters in etorphine-immobilized goats, but the improvement was not as rapid as that observed following the administration of doxapram. However, unlike doxapram, which led to some generalized arousal, CX1942 did not alter the level of immobilization in goats. CX1942 therefore appears to be a useful agent for improving respiration in opioid-immobilized animals. 
Doxapram is widely used by veterinarians as a rescue agent when opioid-induced respiratory depression occurs. In our goats, IV doxapram led to a rapid improvement in all respiratory parameters measured except tidal volume. We compared the effects of the novel agent CX1942 with those of doxapram. In response to the administration of CX1942, $f_{\mathrm{R}}$ and tidal volume did not increase significantly, although presumably the summed interaction of these two variables resulted in the improvement in minute ventilation at 15 , 20 and 25 minutes. By the end of the immobilization period, ventilation, $\mathrm{PaO}_{2}, \mathrm{SaO}_{2}, \mathrm{PaCO}_{2}$ and $\mathrm{pH}$ in goats that had received $\mathrm{CX} 1942$ were all better than before the administration of CX1942, and no different to values obtained before immobilization. Moreover, at 15, 20 and 25 minutes, there were no differences in any of the respiratory variables measured between goats in the CX1942 and doxapram treatments, respectively. However, $\mathrm{PaO}_{2}$ following CX1942 administration was higher than in the control trial at 20 and 25 minutes, whereas $\mathrm{PaO}_{2}$ following doxapram administration did not differ from that in the control treatment at these time-points.

We have thus demonstrated that CX1942 attenuates etorphine-induced respiratory depression in goats, and that it may be useful for improving the welfare of immobilized wild ungulates. Previous studies investigating the effects of etorphine on respiratory and cardiovascular systems have used goats as a model for wild ungulates because the use of a domesticated animal in a controlled setting limits the confounding effects of a captureinduced stress response, and allows for the better determination of a drug's pharmacodynamic effects (Heard et al. 1990, 1996; Buss \& Meltzer 2001; Meyer et al. 2015). However, the degree of sensitivity to opioid-induced respiratory depression varies amongst species (Burroughs et al. 2012). Thus, it is important that ampakines, such as CX1942, are ultimately tested in species such as white rhinoceros (Ceratotherium simum) and impala (Aepyceros melampus), which are particularly sensitive to the respiratory depressant effects of opioids (Meyer et al. 2010; Haw et al. 2014).

Although goats may not be as sensitive to opioids as impala, there are similarities in opioid pharmacodynamics in these two species. The initial etorphine-induced decreases in $\mathrm{PaO}_{2}$ and $\mathrm{SaO}_{2}$, with minimum values at 5 minutes post-administration, followed by a gradual increase in oxygenation as in our control treatment, are similar to those observed in impala (Meyer et al. 2010). The improvement in oxygenation in goats during the control trial, however, was mild and the etorphine-induced hypoxaemic response was not corrected at any time-point during the immobilization period. Therefore, supportive treatments are often deemed necessary in opioid-immobilized ungulates.

Doxapram, which is primarily a potassium channel antagonist (Van der Schier et al. 2014), is a respiratory stimulant commonly used by wildlife veterinarians in opioid-immobilized animals (Burroughs et al. 2012). It exerts its effects centrally, on the brainstem respiratory centres, and peripherally, on carotid and aortic chemoreceptors (Yost 2006). The profound, short-lived respiratory stimulatory effects observed in the present study were not unexpected. Early experiments in dogs revealed that doxapram is metabolized very quickly when administered IV (Bruce et al. 1965). In neonatal calves, doxapram was found to increase ventilation within 30-60 seconds of its administration (Bleul et al. 2010; Bleul \& Bylang 2012). Indeed, $\mathrm{PaCO}_{2}$ in calves fell from about $47 \mathrm{mmHg}$ to $<30 \mathrm{mmHg}$ in just 30 seconds, after which it began to increase again (Bleul et al. 2010). 
By contrast, ampakines, such as CX1942, have a mode of action that is very different from that of doxapram. The ampakine family of compounds modulates AMPA receptors by binding to an allosteric site within the receptor complex, thereby increasing the duration of glutamate-induced AMPA receptor-gated inward currents (Arai et al. 2004). The respiratory stimulatory effects of ampakines are likely to be widespread and include their action on AMPA receptors within the pre-Bötzinger complex, where it is believed that the primary generation of respiratory rhythm occurs (Smith et al. 1991; Feldman et al. 2013).

That CX1942 did not significantly improve tidal volume or $f_{\mathrm{R}}$ in our study was unexpected. Previous studies of other ampakines in rodent models have shown that ampakines act as powerful stimulants of respiratory frequency and tidal volume after respiratory depression induced by $\mu$-opioid receptor agonists (Ren et al. 2006, 2009). Individual variation in sensitivity to CX1942 may have accounted for the lack of observed differences in tidal volume and $f_{\mathrm{R}}$ in our goats following CX1942 administration. Also, unlike doxapram, ampakines do not alter the normal frequency or amplitude of breathing in animals that do not have respiratory depression (Ren et al. 2006, 2015). We therefore suggest that ampakines should be tested in species that experience greater respiratory depressant effects than do goats. Conversely, doxapram may stimulate respiration to above normal levels, as indicated by the hypocapnia and respiratory alkalosis, which occurred at 2 minutes after doxapram administration in our study. Indeed, doxapram has been found to cause respiratory alkalosis in humans (Yost 2006), and hypocapnia $\left(\mathrm{PaCO}_{2}\right.$ of $<35 \mathrm{mmHg}$ ) in neonatal calves (Bleul et al. 2010). A potential negative consequence of hypocapnia is cerebral vasoconstriction with subsequent cerebral hypoxia (Laffey \& Kavanagh 2002). Based on the relatively short duration of effects of doxapram, it is unlikely that prolonged severe hypocapnia and cerebral hypoxia would occur, but it is important to be aware of this potential side effect of doxapram, especially when working with animals that are physiologically compromised by age or illness.

Another adverse effect of doxapram is that it may lead to increased cardiac oxygen consumption (Bleul et al. 2010) as a result of the doxapram-induced increase in the cardiac workload associated with hypertension and increased cardiac output (Van der Schier et al. 2014), probably as a result of catecholamine release (Yost 2006). The use of doxapram for the improvement of oxygenation is therefore considered with caution nowadays in human medicine (Yost 2006). Other than these cardiovascular alterations, doxapram is known to have a generalized central nervous system stimulatory effect, and, indeed, in human medicine, doxapram has been used to arouse patients in the post-anaesthetic setting, as well as for emergency treatment of drug-induced central nervous system depression (Yost 2006). During wildlife immobilization, the potential arousal effects of doxapram are undesirable.

Based on our crude score of the depth of immobilization in the goats, doxapram resulted in more movement than CX1942. Another ampakine, CX717, was found to augment sedation in humans when it was used to prevent alfentanil-induced respiratory depression (Oertel et al. 2010). Although we were unable to measure the level of analgesia in our goats, evidence from both human (Oertel et al. 2010) and rat (Ren et al. 2009) studies suggests that ampakines do not reduce opioid analgesia. 
Ultimately, the ideal pharmacological solution to opioid-induced respiratory depression in immobilized wildlife is a drug potent enough to be administered with the immobilizing cocktail in a dart, that will not interfere with the opioid's ability to induce catatonic immobilization. In this way, opioid-induced respiratory depression, which is most severe at the beginning of the immobilization period (Meyer et al. 2010), could be prevented, rather than treated, thereby significantly reducing the risk for capture-induced complications.

We administered the supportive treatments after etorphine had taken effect in order to determine if CX1942 is capable of reversing opioid-induced respiratory depression in ungulates. These drugs are currently not available in a formulation suitable for coadministration with the opioid in a dart. Moreover, doxapram's duration of action is so short that, if it were to be administered by dart, its peak effects are likely to have passed by the time the animal becomes completely immobile, and the general central nervous system stimulatory effects of doxapram may delay the onset of immobilization. CX1942, in comparison, has a slower onset of action, but lacks solubility and therefore the volume required of this particular ampakine is too large for delivery in a dart.

Ampakines, such as CX1942, may indeed play an important role in counteracting opioidinduced respiratory depression in wildlife without causing unwanted arousal. If a watersoluble and potent formulation that can be combined in a mixture for delivery by dart can be found, prevention, rather than only reversal, of opioid-induced respiratory depression, as we have demonstrated with CX1942, could be achieved. By correcting etorphine's hypoxaemic effects without reversing immobilization, ampakines may offer a much-needed method of preventing the occurrence of life-threatening, opioid-induced respiratory depression during chemical immobilization of wildlife.

\section{Acknowledgements}

The authors thank the staff of the Central Animal Services of the University of the Witwatersrand for their animal management and technical support, and staff and students of the Brain Function Research Group for their help with animal handling and data collection. We also thank Dr Jun Ren, Research Associate at the University of Alberta, for his guidance and help in acquiring CX1942, and Dr Arnold Lippa, Cortex Pharmaceuticals, Inc. (NJ, USA), for the provision of CX1942. This work was funded by a Faculty Research Committee Grant, University of the Witwatersrand, awarded to AJH, and a Thuthuka grant from the National Research Foundation, South Africa, awarded to LCRM.

\section{Authors' contributions}

AJH: Contributed to the conception of the study, and the acquisition, analysis and interpretation of data, and drafted the first manuscript; LCRM and AF: Contributed to the conception of the study, the interpretation of data and the critical revision of the manuscript for intellectual content; JJG: Contributed to the conception of the study and the critical revision of the manuscript for intellectual content. 


\section{References}

Arai AC, Xia YF, Suzuki E (2004) Modulation of AMPA receptor kinetics differentially influences synaptic plasticity in the hippocampus. Neuroscience 123, 1011-1024.

Bleul B, Bylang T (2012) Effects of doxapram, prethcamide and lobeline on spirometric, blood gas and acid-base variables in healthy new-born calves. Vet J 194, 240-246.

Bleul U, Bircher B, Jud RS et al. (2010) Respiratory and cardiovascular effects of doxapram and theophylline for the treatment of asphyxia in neonatal calves. Theriogenology 73, 612-619.

Bruce RB, Pitts JE, Pinchbeck F et al. (1965) Excretion, distribution, and metabolism of doxapram hydrochloride. J Med Chem 8, 157-164.

Burroughs R, Meltzer D, Morkel P (2012) Applied pharmacology. In: Chemical and Physical Restraint of Wild Animals (2nd edn). Kock MD, Meltzer D, Burroughs R (eds). IWVS, South Africa. pp. 53-62.

Buss $P$, Meltzer D (2001) Changes in respiratory function following intramuscular administration of etorphine in Boer goats (Capra hircus). J S Afr Vet Assoc 72, 137-142.

Dahan A, Aarts L, Smith TW (2010) Incidence, reversal, and prevention of opioid-induced respiratory depression. Anesthesiology 112, 226-238.

El Mallah MK, Pagliardini S, Turner SM et al. (2015) Ampakines enhance respiratory output in a murine model of Pompe disease. Am J Respir Cell Mol Biol 53, 326-335.

Feldman JL, Del Negro CA, Gray PA (2013) Understanding the rhythm of breathing: so near, yet so far. Annu Rev Physiol 75, 423-452.

Funk GD, Smith JC, Feldman JL (1993) Generation and transmission of respiratory oscillations in medullary slices: role of excitatory amino acids. J Neurophysiol 70, 1497-1515.

Greer JJ, Smith JC, Feldman JL (1991) Role of excitatory amino acids in the generation and transmission of respiratory drive in neonatal rats. J Physiol 437, 727-749.

Haw A, Hofmeyr M, Fuller A et al. (2014) Butorphanol with oxygen insufflation corrects etorphineinduced hypoxaemia in chemically immobilized white rhinoceros (Ceratotherium simum). BMC Vet Res 10, 253.

Heard DJ, Kollias GV, Buss D et al. (1990) Comparative cardiovascular effects of intravenous etorphine and carfentanil in domestic goats. J Zoo Wildl Med 21, 166-170.

Heard DJ, Nichols WW, Buss D et al. (1996) Comparative cardiopulmonary effects of intramuscularly administered etorphine and carfentanil in goats. Am J Vet Res 57, 87-96.

Kilkenny C, Browne WJ, Cuthill IC et al. (2010) Improving bioscience research reporting: the ARRIVE Guidelines for Reporting Animal Research. PLOS Biol 8, e1000412.

Lynch G (2006) Glutamate-based therapeutic approaches: ampakines. Curr Opin Pharmacol 6, 82-88. 
Meyer LCR, Fuller D, Mitchell D (2006) Zacopride and 8-OH-DPAT reverse opioid-induced respiratory depression and hypoxia but not catatonic immobilization in goats. Am J Physiol Regul Integr Comp Physiol 290, R405-R413.

Meyer LCR, Hetem RS, Fick LG et al. (2010) Effects of serotonin agonists and doxapram on respiratory depression and hypoxemia in etorphine-immobilized impala (Aepyceros melampus). $J$ Wildl Dis 46, 514-524.

Meyer LCR, Hetem RS, Mitchell D et al. (2015) Hypoxia following etorphine administration in goats (Capra hircus) results more from pulmonary hypertension than from hypoventilation. BMC Vet Res $11,18$.

Oertel BG, Felden L, Tran PV et al. (2010) Selective antagonism of opioid-induced ventilatory depression by an ampakine molecule in humans without loss of opioid analgesia. Clin Pharmacol Ther 87, 204-211.

Pace RW, Mackay DD, Feldman JL et al. (2007) Inspiratory bursts in the preBötzinger complex depend on a calcium-activated non-specific cation current linked to glutamate receptors in neonatal mice. J Physiol 582, 113-125.

Pattinson KTS (2008) Opioids and the control of respiration. Br J Anaesth 100, 747-758.

Ren J, Poon BY, Tang Y et al. (2006) Ampakines alleviate respiratory depression in rats. Am J Respir Crit Care Med 174, 1384-1391.

Ren J, Ding X, Funk GD et al. (2009) Ampakine CX717 protects against fentanyl-induced respiratory depression and lethal apnea in rats. Anesthesiology 110, 1364-1370.

Ren J, Ding X, Greer JJ (2012) Respiratory depression in rats induced by alcohol and barbiturate and alleviation by ampakine CX717. J Appl Physiol 113, 1004-1011.

Ren J, Lenal F, Yang M et al. (2013) Co-administration of the ampakine CX717 with propofol reduces respiratory depression and fatal apneas. Anesthesiology 118, 1437-1445.

Ren J, Ding X, Greer JJ (2015) Ampakines enhance weak endogenous respiratory drive and alleviate apnea in perinatal rats. Am J Respir Crit Care Med 191, 704-710.

Smith JC, Ellenberger HH, Ballanyi K et al. (1991) Pre-Bötzinger complex: a brainstem region that may generate respiratory rhythm in mammals. Science 254, 726-729.

Van der Schier R, Roozekrans M, Van Velzen M et al. (2014) Opioid-induced respiratory depression: reversal by non-opioid drugs. F1000Prime Rep 6, 79.

Yost CS (2006) A new look at the respiratory stimulant doxapram. CNS Drug Rev 12, 236-249. 